\title{
Assessing the success behind the use of education management information systems in higher education
}

\author{
José Martins ${ }^{\mathrm{a}, \mathrm{b}, *}$, Frederico Branco ${ }^{\mathrm{a}}$, Ramiro Gonçalves ${ }^{\mathrm{a}}$, Manuel Au-Yong-Oliveira ${ }^{\mathrm{c}}$, \\ Tiago Oliveira $^{\mathrm{d}}$, Mijail Naranjo-Zolotov ${ }^{\mathrm{d}}$, Frederico Cruz-Jesus ${ }^{\mathrm{d}}$ \\ a INESC TEC and University of Trás-os-Montes e Alto Douro, Vila Real, Portugal \\ b Polytechnique Institute of Bragança - EsACT, Mirandela, Portugal \\ ${ }^{c}$ GOVCOPP, Department of Economics, Management, Industrial Engineering and Tourism, University of Aveiro, $3810-193$ Aveiro, Portugal \\ ${ }^{\mathrm{d}}$ NOVA Information Management School (NOVA IMS), Universidade Nova de Lisboa, Campus de Campolide, 1070-312 Lisboa, Portugal
}

\section{A R T I C L E I N F O}

\section{Keywords:}

EMIS

IS success

Higher education level

Students' performance

\begin{abstract}
A B S T R A C T
The continuous use of dynamic and disruptive ICT as energizing elements of the educational process is a reality of current days, where millennials are the centre of an education paradigm in which students are much more inclined to use technologies than enrolling in a traditional nondigital course. Considering education management information systems (EMIS) capacities to collect, analyse, process and publish information and data, it is easy to perceive their relevance to both education organizations and students. Nevertheless, and despite EMIS complexity and inherent possibilities, the existing literature does not provide for a detailed characterization on the impact these systems might have on students' success. Thus, this research focuses on understanding the use of EMIS by students and the arising of net benefits; it introduces an EMIS success model which posits that to ensure net benefits for students, education institutions must safeguard that their education management information systems are of high quality, while at the same time students are maintained satisfied with the system and engage in continuous use. To assess the posed model, an empirical study has been performed, involving students from higher education institutions. Findings from the study allow us to perceive that, as information systems (IS) success models state, EMIS use and students' satisfaction are predictors of net benefits. This same model also claims that the available information quality and EMIS inherent service quality are also strong determinants of both continuous EMIS use and student satisfaction.
\end{abstract}

\section{Introduction}

When analysing educational history, one can perceive the inception of the association between learning and schooling. As a consequence, the majority of existing learners (students) are enrolled in traditional courses and learning programs designed to serve the great majority and with little to no customization to the individual personal profile (Collins and Halverson, 2018). Nevertheless, education is still one of the most relevant determinants of both individual success and social integration.

As argued by both Academia and Business (Moreira and Rocha, 2018), the digital age in which we are living has led to the

\footnotetext{
* Corresponding author.

E-mail addresses: jmartins@utad.pt (J. Martins),fbranco@utad.pt (F. Branco), ramiro@utad.pt (R. Gonçalves), mao@ua.pt (M. Au-Yong-Oliveira), toliveira@novaims.unl.pt (T. Oliveira), mijail.naranjo@isegi.unl.pt (M. Naranjo-Zolotov), fjesus@novaims.unl.pt (F. Cruz-Jesus).
} 
creation of very significant amounts of data that must be properly structured, analysed and accurately presented in order for citizens to be able to seize the benefits behind these sets of information. This same assumption can be translated to education, given the increase in the complexity associated with the entire education management process, whether we are analysing it from the students' perspective or from the education institution's eyes (Davis and Sumara, 2014). Consequently, education institutions have been engaged in incorporating information systems and technologies that allow for a more market-efficient management of their resources and "business" and, in parallel, also allow for students to actively interact with their courses' entire scope (professors, learning materials, assessments, and colleagues), thus triggering both parties' performance and success (Vicent et al., 2015).

As previously argued by Martins et al. (2019), the existing literature does not provide for an extensive indication of the possible determinants of both EMIS use by students and the inherent net benefits. This would, for sure, help to increase the possibilities behind the use of these systems for both students and organizations. Therefore, a proposal for an EMIS success model drawn from Delone and McLean (2003) and Balaban et al. (2013) has been developed. This model aims at raising awareness on the possible direct impacts that EMIS quality might have on the systems' actual (and continuous) use, on students' satisfaction and regarding the emergence of net benefits. To confirm these hypotheses, an empirical study focusing on Portuguese higher education students from three different universities has been performed.

The paper is organized as follows: in the second section we make a focused presentation and analysis of the educational use of information and communication technologies (ICT), of the concept of EMIS and of the existing literature on both information systems' success and education-related information systems' success. In the third section we conceptualize the research model. This is followed by the presentation of the design, methodology, and results of this research. Finally, the achieved results are discussed, and possible further developments of this research are outlined.

\section{Conceptual scene}

\subsection{Information systems technologies and education}

Young people currently attending university education (i.e., millennials) have long been accustomed to using the Internet and interacting through different digital devices with their friends and networks. For higher education institutions to communicate effectively and efficiently with these generations, they must understand the use of contemporary digital media as an essential strategy for successful teaching (Au-Yong-Oliveira et al., 2018).

The use of online platforms allows students to have a high degree of freedom in managing their time by allowing registration, access to content and other information regarding the courses remotely (University of Stuttgart, 2016). The increasing internationalization of educational delivery by universities requires this flexibility, which can only be achieved through a digital system. Additionally, due to the aging of population in most industrialized countries, there is a need to attract already employed people, who are less willing to attend courses during non-working hours. This condition may alienate potential students if the educational offer does not include technological means that substantially reduce direct contact with the university.

The ability to use the Internet is an important requirement for working with online digital platforms. Current broadband connections are heavily disseminated outside and within university campuses, and free wireless network access is offered by cities in most countries. These infrastructures allow teachers to incorporate in their lessons, in real time, content based on searches in search engines, as well as videos (e.g., YouTube) (Arkorful and Abaidoo, 2015).

E-learning platforms (e.g., Moodle) are excellent tools to support the teaching process. Through these tools, students can be asked to perform tasks or to submit assessments, or even have shared spaces (i.e., forums) for collaboration and support from more advanced students (Greenhow et al., 2009). Students who cannot regularly attend the classroom can benefit from the use of elearning platforms. Universities are streamlining lessons with video, allowing students to see and review them, stimulating a learning process more suited to the rhythm of everyone, and not forcing a specific date/time for lesson assimilation. These platforms are not intended to replace the teacher. They are a complementary tool to face-to-face teaching that allows the use of innovative and dynamic tools to stimulate the students' learning process (Masino and Niño-Zarazúa, 2016).

There are several online platforms that offer a collaborative space (e.g., Padlet) accessible anywhere, anytime. These are an ideal tool for promoting, recording and tracking creative processes, both during and after class. Alternatively, partner network platforms (e.g., Facebook, Instagram, and Snapchat) can be used, although they make it difficult for the student to be involved in the class because they are designed for entertainment (Deng and Tavares, 2013).

\subsection{Education management information systems - EMIS}

Information systems have a key role in the development of organizations, enabling them to reduce costs, increase productivity, efficiency and effectiveness, improve both product and service quality, and optimize decision-making (Tarafdar and Gordon, 2007). Hence, considering the "Information" importance to IS, it is critical these are designed to generate knowledge and organizational intelligence. Universities emerge as great producers and consumers of information and knowledge, largely due to the academic milieu dynamic and unpredictable environment, making these resources essential to be able to make the best decisions at the right moment (Välimaa and Hoffman, 2008).

As education institutions need to continuously increase the level and density of business knowledge in order to take business decisions that allow maintaining their competitiveness, their necessity for information systems that enable a transversal level of integration and have the ability not only to acquire but also to produce (and publish) information also grows significantly (Bøe et al., 
2015).

As argued by Cash (2015), Education Management Information Systems are perceived by existing literature under a wide range of conceptual terms, from student information systems, student management systems, information technologies in education management, and also as "simple" information systems. From a theoretical perspective, education management information systems (EMIS) can be perceived as information systems (IS) that are able to produce, manage and disseminate educational data and information as part of their IT infrastructure (Tolley and Shulruf, 2009). The merging of this initial conceptualization with other theoretical conceptualizations and practical characterizations on the topic, such as Bessa et al. (2016) and Deng and Tavares (2013), allowed for an evolution of the initial concept to the point of being conceived as systems that allow for a dual perspective on its use: 1) when being used by those managing the education institutions (thus allowing to achieve the necessary information to make strategic decisions); and 2) when in use by students to manage their individual learning process, to collect and analyse the information necessary for any type of decision making concerning their learning activities, and also to actively interact with all stakeholders of the educational process (i.e. other students and professors) (Holsapple and Lee-Post, 2006).

Despite being conceptually considered as a tool for those with planning and administrative roles to manage their educational system (i.e. school) in a more efficient and effective manner, the reality is that each of these systems has been evolving to the point of being a more complex system, encompassing both its initial features and course-related features (Abdul-Hamid, 2017; Akaranga and Makau, 2016).

When analysed on the motives behind the development of complex EMIS, schools and particularly universities tend to acknowledge that their effort is totally focused on triggering both organizational performance and students' (learning) success (Bessa et al., 2016). Nevertheless, when focusing millennials, the main population currently enrolled in universities, the use of IS and the systems' impact on their learning process and their success as students is controversial. If, for instance, some authors assume these systems must incorporate a more emotional component (Faria et al., 2017), others assume that EMIS should assume a motivational feature while serving, at the same time, for both students and organizations to compare their current status and past evolution with existing national and international data (Au-Yong-Oliveira et al., 2018). On the other hand, researchers are decomposing EMIS into smaller parts and trying to study their impact into students' success (McGill and Klobas, 2009).

\subsection{Information systems success}

The definition of "success" in the assessment of information systems has not been agreed in the literature as a single concept. Measurement of success in information systems is considered as a multidimensional concept, where each dimension may be an indicator of success. Many studies address information systems success as a measurement of the continued usage (Kim and Malhotra, 2005; Sun, 2013). Albeit, the perspective of success can vary depending on the information system being studied. For instance, success in the context of e-participation systems can be an indicator of citizen satisfaction and adoption in the long term (Zolotov et al., 2017); and in the information kiosks context it can be a measure of the frequency of use (Wang and Shih, 2009); and still further in the field of e-learning, success has been studied as continued satisfaction for students and instructors (Al-Samarraie et al., 2017).

One of the most well-known models for assessing information systems success is Delone and McLean (2003, 2004), which integrates six dimensions of information system success: information quality, system quality, service quality, use, user satisfaction, and net benefits, which are described in further detail in the next section. This mode has been used to evaluate different types of information systems. For instance, Wang and Liao (2008) evaluated the success of e-government, finding all relationships but system quality significant; Floropoulos et al. (2010) used DeLone and McLean to evaluate success in e-taxation systems from the perspective of the employees, and found all constructs to be significant, except system quality over user satisfaction.

Assessing success in education information systems can be critical to reduce the digital divide that is related to the level of education (Cruz-Jesus et al., 2016), moreover, it may help to engage adult learners online (Yoo and Huang, 2013). Education management information systems (EMIS) may refer to a wide set of information systems tools, as for instance the massive open online courses (MOOC) (Sanchez-Gordon and luján-Mora, 2016) or the e-learning systems (Al-Samarraie et al., 2017). Previous studies have evaluated different tools in the field of online education using the DeLone and McLean model. For instance, (Yang et al., 2017) found that system quality, course quality, and service quality were a significant antecedent for the continuance intention of the students to use MOOCs, and Cidral et al. (2017) found that collaboration quality, information quality, and user satisfaction help to explain the usage of e-learning.

\section{Research model}

During recent years, information systems and technologies (IST) have been the basis for not only new methods of teaching and learning, but also for new education management procedures (Martins et al., 2015). Drawing on this assumption, the intent of this research was to assess the triggers behind EMIS success from the students' perspective. Drawing further on this assumption and after a careful analysis of the arguments on IS success presented by both DeLone and McLean (2016) and Balaban et al. (2013), and also considering other relevant literature on the topic, we have reached a research model proposal for explaining the possible success behind the student use of EMIS in higher education.

According to the existing literature, when assessing information system quality, their inherent variables (information quality, system quality and service quality) must be analysed and scrutinized in order to understand if their inherent relations or mere existence has any type of influence on the overall IS success (Michel and Cocula, 2017). Drawing on Laumer et al. (2017) IS success 


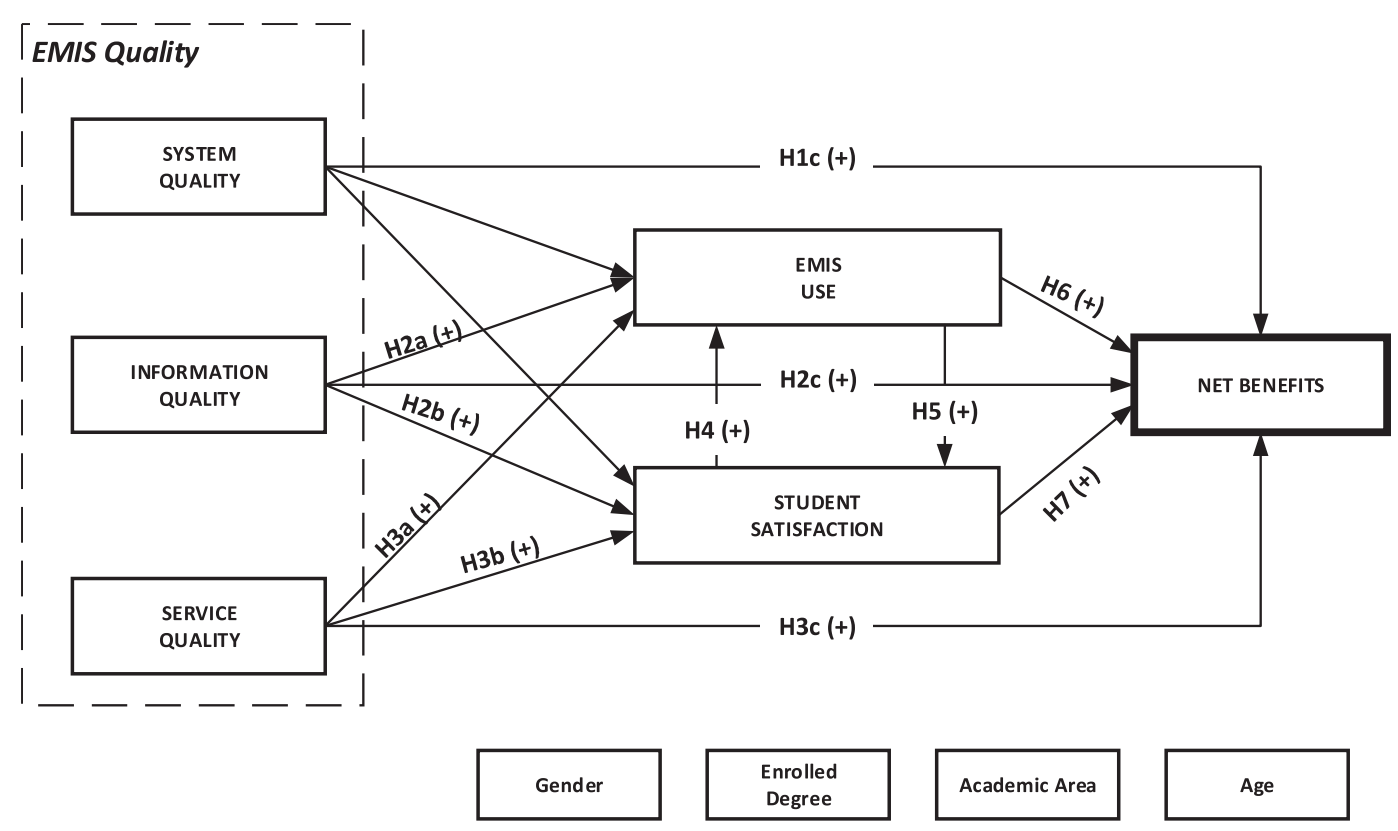

Fig. 1. Research Model.

might be perceived as the net benefits that arise from using the referred systems and the influence on those same users' (personal and professional) lives that the IS might represent (see Fig. 1).

When performing our research, an assumption was made that the most positive levels of success associated with using an EMIS were reachable by merging the impacts of three major scopes: the EMIS overall quality, the use of the referred systems by students, and their level of satisfaction with the artefact. Considering the wide variety of profiles associated with higher education students, we have also assumed the need to understand the effect that individual characteristics (such as the students' gender, age, degree and academic area of the course in which he or she is enrolled) might have on the process of securing benefits from using a given EMIS.

\subsection{System quality}

As existing literature on IS success argues, system quality refers to the features and characteristics that users expect to be available when using the referred system (Delone and McLean, 2003). Examples of these features are the system's ease of use, its flexibility and scalability, reliability, and response times. Hong et al. (2006) reason that system quality is one of the most relevant determinants for post-adoption behaviours, hence influencing the perception of success for the users of the system. This same argument is provided by Wu and Wang (2006) for whom the existence of a positive association between IS quality and the user perception of net benefits tends to be realistic in a wide variety of situations. In a more detailed approach, the information system is expected to allow for users to efficiently and effectively access information and actively interact and participate in it (Zheng et al., 2013).

When analysing the adoption of education-related information systems and technologies and users' perceived satisfaction and success, the overall technical and functional quality of the system has been at various moments considered of the utmost relevancy (Liaw, 2008; McGill and Klobas, 2009; Navimipour and Zareie, 2015). As argued by Martins et al. (2019) and Walji et al. (2014), when referring to an EMIS technical and functional quality, we should acknowledge that this overall perception encompasses both the system's capacity to be properly and easily used and its ability to correctly and continuously provide all the features that have been specified as necessary functional requirements.

Hence, by perceiving the relevance of the system quality to the adoption of EMIS by all members of a university community, and particularly by students, we posed the following hypotheses:

H1a: A high-quality system will positively influence users towards using it.

H1b: A high-quality system will positively trigger students' satisfaction towards its use.

H1c: A high-quality system will positively trigger the arising of net benefits for students.

\subsection{Information quality}

According to Chavez et al. (2015), information quality is considered to be one of the triggers behind IS integration and use. Conceptually, information quality refers to the quality of the IS outputs: its accuracy, the inherent level of readability and interpretation, and its relevance to the user (Gable et al., 2008).

As education-related organizations become particularly aware of the importance of having information systems that not only fulfil all functional requirements but also produce high-quality information (Mavetera et al., 2017), this same effect is also being identified 
in students' behaviour (Waheed et al., 2016) who, as Wong and Huang (2015) argue, are more likely to use a given EMIS if the information it produces is relevant and useful to their learning process.

EMIS are very relevant for students in order for them to be able to not only have access to all of the available information on their courses, but also to their institutional relationship with their university (Hua and Herstein, 2003; Koç et al., 2016). Thus, we have hypothesized the following:

H2a - EMIS capacity to produce high-quality information will positively influence its use by students.

$H 2 b$ - EMIS capacity to produce high-quality information will positively influence student satisfaction in using it.

H2c - EMIS capacity to produce high-quality information will influence the arising of net benefits resulting from using the system.

\subsection{Service quality}

According to Ahn et al. (2007) and Oliveira et al. (2014) IST users tend to demonstrate positive behaviour attitudes towards using a given technology if it has the ability to be reliable, have fair levels of performance and availability, and have higher levels of security and privacy assurance. As argued by Zhou (2013), the assurance of service quality is even more relevant for online services and platforms than what it is for traditional services. From the perspective of Gorla et al. (2010) and Branco et al. (2016a,b), the services associated with IST must be of the highest quality given the need, presented by both internal and external system users, for dependable services which ensure a successful continuous use.

The available literature on the use of education-aimed information systems and technologies reasons that when the service associated with the technology component is considered to be of high quality, students tend to increase their learning efficacy (Lee and Lee, 2008). In a similar vein, Balaban et al. (2013) also reinforce the relevance of high quality learning-related information systems to the students' adoption of the system itself. Hence, and drawing on Yousapronpaiboon (2014) research, from our perspective, in order for an EMIS to be considered as being a usable tool it must ensure the existence of synchronous and asynchronous online help features, the existence of both technical and user manual, the (semi)permanent availability of a helpdesk service, and also the existence of online information on how to use the systems.

Hence, drawing on the presented arguments we have hypothesized the following:

$H 3 a-E M I S$ inherent service quality will act as a positive trigger to its use.

$H 3 b-E M I S$ inherent service quality will act as a positive influence on student satisfaction.

$H 3 c-E M I S$ inherent service quality will act as a positive influence on the arising of net benefits.

\subsection{EMIS use}

The existing literature holds that the actual usage of a given information system refers to the degree to which an individual uses, with some frequency, nature and duration, the entire spectrum of features made available by the system (Aldholay et al., 2018). In a complementary note, Tam and Oliveira (2017) also argue that the continuous use of a given information system or technology that presents high quality information, supported by an easy to use and reliable technical and functional structure and that has fair levels of customer/user service and support, usually leads to an increased user satisfaction.

According to Martins et al. (2019) research, one can assume the existence of a significant degree of interdependency between the use of a given education-related IS by students and their overall satisfaction towards the system. Drawing on Balaban et al. (2013) argument this same positive relation tends to arise between the continuous use of a given IS by students and the inherent net benefits to them of its usage. Thus:

H4: EMIS usage by students has a positive effect on their satisfaction in using the system.

H6: EMIS usage by students has a positive effect on the arising of net benefits for the student.

\subsection{Student satisfaction}

User satisfaction towards a given IST refers to the positive emotions demonstrated by the individual when interacting with it (Cenfetelli et al., 2008). When addressing the acceptance and use of ISTs, one can perceive the proven relation between the degree of satisfaction towards a given technology and the user intention to not only intend to use it (Park and Kim, 2014), but also to intend to continuously use it (Hsiao et al., 2016).

According to Delone and Mclean (2004) and Baraka et al. (2013), the existence of a good level of user satisfaction towards a given IST will impact the arising of net benefits associated with the use of the referred technology, hence the interpretation that when a user is satisfied with an information system or technology, his or her individual success levels are triggered.

Hence, drawing on what was mentioned above, we propose the following hypotheses:

H5: EMIS net benefits have a positive impact on EMIS use.

H7: EMIS net benefits have a positive impact on student satisfaction.

\section{Empirical study}

\subsection{Measurement}

All constructs have been adapted, with slight modifications regarding the existing literature (see Appendix A). The measurement 
of the constructs has been achieved via a seven-point Likert scale ranging from " 1 - strongly disagree" to " 7 - strongly agree". For the constructs drawn from the literature to be used, some changes have been made, focusing on education management information systems. Considering the idealized assumptions on the effect that students' personal traits might have on our research, we have also included four demographic questions relating to gender, academic degree and area, as well as age. The collection of responses was made using printed versions of the questionnaire manually distributed to students from three major Portuguese universities.

\subsection{Data}

As advised by Tam and Oliveira (2017), the distributed questionnaire was initially developed in English and its final version was independently translated to Portuguese by a professional translator, expert in both English and Portuguese, and consequently translated back into English by a Cambridge C2-Proficiency English expert, thus ensuring translation equivalence.

To ensure that the developed questionnaire had the necessary validity and feasibility, a pilot study was performed. Considering the need to ensure the necessary variety of students in this initial target group, a set of 30 answers was collected from students from each one of the three universities involved in this research. The results achieved indicated that all scales might be considered valid and reliable, and that the developed survey represents an accurate tool to access the quality of the proposed model. As a direct consequence, the data from this pilot survey has been included in the main survey.

In October 2017, the questionnaire was shared with a total of 450 university students from three different Portuguese universities, 403 of which were considered as valid responses, i.e. complete answers, thus representing an overall response rate of almost $90 \%$. The sample is made up by 162 females (40\%) and 242 males (60\%). The average age recorded was 23 years old, and the youngest students to ensure complete answers were 18 years old, while the oldest were 38 years old. In terms of distribution, the big majority of respondents (more than 60\%) were over 23 years of age. Regarding the degree in which students were enrolled, 189 students were enrolled in an undergraduate degree (46,9\%), 290 were enrolled in a master's degree $(47,1 \%)$ and 24 were enrolled in other, more advanced (PhD or Post-doc) degrees (6\%). As concerns students' academic area, 142 (35\%) of the respondents were enrolled in courses belonging to the Sciences and Technologies field of study, 236 (50\%) belonged to courses of the Social and Human Sciences area, and the remaining respondents $(6 \%)$ were from other fields of study.

\section{Results}

We used partial least squares (PLS) to estimate the research model through Smart PLS 3.0 M3 software (Ringle et al., 2015). In the next subsection we estimate the measurement model and the structural model.

\subsection{Measurement model}

All used constructs have been established by reflective indicators. The measurement model was evaluated based on internal consistency, reliability, convergent validity, and discriminant validity. In what concerns internal consistency, we used Cronbach's Alpha (CA) and composite reliability (CR), and both should be higher than 0.7 (Henseler et al., 2009). Based on Table 1 we can conclude that the CA and CR are higher than 0.7, which reveals that our constructs have internal consistency. Straub (1989) and Hair et al. (2013) argue that the used constructs have the conditions to be considered reliable as their loadings are above 0.700 , based on Table 2 the loadings fulfilling the required criteria. Hence, the measuring instrument presented good indicator reliability. According to Fornell and Larcker (1981), the average variance extracted (AVE) should be used as a criterion to assess convergent validity, the AVE should be greater than 0.500 . In Table 1 we can see that all constructs present an AVE greater than 0.500, and so consequently we can conclude that all constructs have convergent validity.

To assess discriminant validity, we have analysed three criteria: 1) the square root of AVE should be higher than the correlations between constructs (please see Table 1); 2) the loadings should be larger than the cross-loadings (please see Table 2); 3) According to Henseler et al. (2015), the Heterotrait-monotrait ration of correlations (HTMT) should be lower than 0.900 (please see Table 3). Given that all criteria have been fulfilled, we conclude that all constructs have discriminant validity.

Table 1

Descriptive statistics, correlation, cronbach's alpha, composite reliability (CR) and average variance extracted (AVE).

\begin{tabular}{|c|c|c|c|c|c|c|}
\hline & SysQ & IQ & SerQ & EMIS use & SS & NB \\
\hline System quality (SysQ) & 0.842 & & & & & \\
\hline Information quality (IQ) & 0.744 & 0.853 & & & & \\
\hline Service quality (SerQ) & 0.573 & 0.566 & 0.858 & & & \\
\hline EMIS use & 0.543 & 0.469 & 0.567 & 0.915 & & \\
\hline Student satisfaction (SS) & 0.670 & 0.691 & 0.571 & 0.539 & 0.879 & \\
\hline Net benefits (NB) & 0.608 & 0.679 & 0.641 & 0.588 & 0.760 & 0.841 \\
\hline Mean & 4.877 & 5.069 & 4.442 & 4.293 & 4.954 & 4.659 \\
\hline Standard deviation (SD) & 1.143 & 1.100 & 1.240 & 1.406 & 1.268 & 1.164 \\
\hline Cronbach's alpha & 0.897 & 0.906 & 0.910 & 0.903 & 0.854 & 0.861 \\
\hline Composite reliability (CR) & 0.924 & 0.930 & 0.933 & 0.939 & 0.911 & 0.906 \\
\hline
\end{tabular}

Notes: Values in diagonal (bold) are square root of average variance extracted (AVE). 
Table 2

Loadings and Cross-loadings.

\begin{tabular}{|c|c|c|c|c|c|c|}
\hline & SysQ & InQ & SerQ & EMIS use & SS & NB \\
\hline SYSQ1 & 0.835 & 0.609 & 0.373 & 0.370 & 0.579 & 0.455 \\
\hline SYSQ2 & 0.859 & 0.594 & 0.527 & 0.493 & 0.542 & 0.522 \\
\hline SYSQ3 & 0.862 & 0.638 & 0.525 & 0.523 & 0.563 & 0.516 \\
\hline SYSQ4 & 0.875 & 0.632 & 0.496 & 0.447 & 0.562 & 0.534 \\
\hline SYSQ6 & 0.775 & 0.656 & 0.480 & 0.444 & 0.576 & 0.525 \\
\hline IQ1 & 0.636 & 0.842 & 0.480 & 0.309 & 0.538 & 0.538 \\
\hline IQ2 & 0.626 & 0.840 & 0.480 & 0.420 & 0.544 & 0.545 \\
\hline IQ3 & 0.603 & 0.848 & 0.428 & 0.340 & 0.578 & 0.557 \\
\hline IQ6 & 0.683 & 0.881 & 0.483 & 0.414 & 0.641 & 0.587 \\
\hline IQ7 & 0.623 & 0.852 & 0.536 & 0.493 & 0.631 & 0.654 \\
\hline SerQ2 & 0.441 & 0.441 & 0.815 & 0.465 & 0.444 & 0.520 \\
\hline SerQ3 & 0.482 & 0.504 & 0.906 & 0.452 & 0.516 & 0.579 \\
\hline SerQ4 & 0.509 & 0.526 & 0.883 & 0.447 & 0.514 & 0.551 \\
\hline SerQ5 & 0.557 & 0.486 & 0.824 & 0.634 & 0.485 & 0.557 \\
\hline SerQ6 & 0.456 & 0.467 & 0.858 & 0.415 & 0.486 & 0.537 \\
\hline EMIS use1 & 0.530 & 0.446 & 0.529 & 0.909 & 0.507 & 0.529 \\
\hline EMIS use2 & 0.462 & 0.420 & 0.494 & 0.933 & 0.498 & 0.533 \\
\hline EMIS use3 & 0.497 & 0.420 & 0.533 & 0.901 & 0.473 & 0.552 \\
\hline SS1 & 0.690 & 0.670 & 0.562 & 0.565 & 0.871 & 0.709 \\
\hline SS3 & 0.551 & 0.591 & 0.448 & 0.398 & 0.880 & 0.628 \\
\hline SS4 & 0.509 & 0.550 & 0.485 & 0.442 & 0.886 & 0.659 \\
\hline NB2 & 0.537 & 0.561 & 0.612 & 0.562 & 0.686 & 0.877 \\
\hline NB3 & 0.523 & 0.626 & 0.597 & 0.492 & 0.736 & 0.887 \\
\hline NB4 & 0.493 & 0.597 & 0.500 & 0.453 & 0.627 & 0.856 \\
\hline NB9 & 0.498 & 0.496 & 0.425 & 0.474 & 0.476 & 0.736 \\
\hline
\end{tabular}

Values in bold are the loadings of each indicator.

Table 3

Heterotrait-monotrait ratio of correlations (HTMT).

\begin{tabular}{llllll}
\hline & SysQ & IQ & SerQ & EMIS use & SS \\
\hline System quality (SysQ) & & & & & \\
Information quality (IQ) & 0.824 & & & & \\
Service quality (SerQ) & 0.629 & 0.620 & 0.621 & 0.606 & 0.872 \\
EMIS use & 0.601 & 0.512 & 0.642 & 0.668 & \\
Student satisfaction (SS) & 0.759 & 0.776 & 0.716 & \\
Net benefits (NB) & 0.693 & 0.763 & & \\
\hline
\end{tabular}

\subsection{Structural model}

First, a test was done to validate the multicollinearity of all constructs based on the variance inflation factor (VIF). Given that the VIF values range from 1.72 to 2.77 , thus staying below the threshold of 5 , one can acknowledge the absence of multicollinearity among the variables (Hair et al., 2016). The model estimation was estimated from bootstrapping with 5000 resamples. Fig. 2 shows the path coefficients, statistical significance, and R squares for model 1 (EMIS use explains student satisfaction) and model 2 (student satisfaction explains EMIS use). Table 4 shows all the calculated results for the model constructs effects.

Model 1 (EMIS use explains student satisfaction) explains $40.9 \%$ of the variation in EMIS use and model 2 (student satisfaction explains EMIS use) explains $43.2 \%$ of the variation in EMIS use. For both models system quality $(\hat{\beta}=0.276, \mathrm{p}<0.01$ in model 1 , $\widehat{\beta}=0.211, \mathrm{p}<0.01$ in model 2$)$, service quality $(\widehat{\beta}=0.372, \mathrm{p}<0.01$ in model $1, \widehat{\beta}=0.325, \mathrm{p}<0.01$ in model 2$)$, and student satisfaction $(\hat{\beta}=0.299, \mathrm{p}<0.01)$ are statistically significant, thus confirming hypotheses H1a, H3a, and H5. Only H2a is not supported in both models.

Model 1 (EMIS use explains student satisfaction) explains $57.6 \%$ of the variation in student satisfaction and model 2 (student satisfaction explains EMIS use) explains $56.0 \%$ of the variation in student satisfaction. For both models, system quality ( $\widehat{\beta}=0.235$, $\mathrm{p}<0.01$ in model $1, \widehat{\beta}=0.283, \mathrm{p}<0.01$ in model 2$)$, information quality $(\widehat{\beta}=0.361, \mathrm{p}<0.01$ in model $1, \widehat{\beta}=0.365$, $\mathrm{p}<0.01$ in model 2$)$, service quality $(\hat{\beta}=0.141, \mathrm{p}<0.01$ in model $1, \widehat{\beta}=0.205, \mathrm{p}<0.01$ in model 2$)$, and EMIS use $(\hat{\beta}=0.170, \mathrm{p}<0.01)$ are statistically significant, thus confirming hypotheses H1b, H2b, H3b, and H4. Only H2a is not supported in both models.

Models 1 and 2 explain $68.1 \%$ of the variation in net benefits. For both models information quality $(\widehat{\beta}=0.232, \mathrm{p}<0.01$ in model 1 and 2$)$, service quality $(\widehat{\beta}=0.206, \mathrm{p}<0.01$ in model $1, \hat{\beta}=0.205, \mathrm{p}<0.01$ in model 2 ), EMIS use $(\hat{\beta}=0.152$ in both models), and student satisfaction $(\widehat{\beta}=0.440, \mathrm{p}<0.01$ in model $1, \widehat{\beta}=0.441, \mathrm{p}<0.01$ in model 2), are statistically significant, thus confirming hypotheses H2c, H3c, H6 and H7. Only H1c is not supported in both models. 


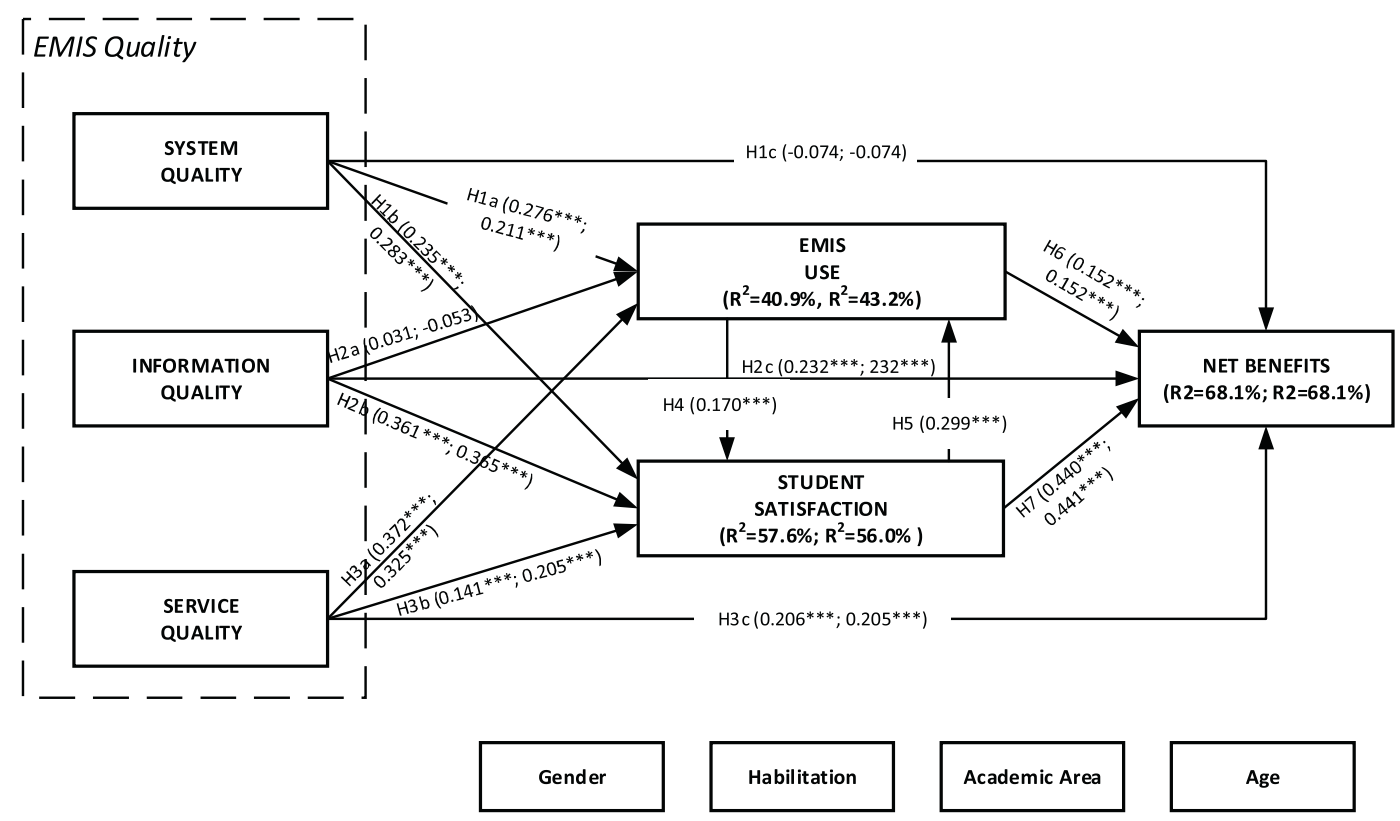

Fig. 2. structure model results. Note: In parenthesis are respectively the path coefficient of model 1 (EMIS use explains student satisfaction) the first value, and model 2 (student satisfaction explains EMIS use) the second value; ${ }^{* *} \mathrm{p}<0.01$; ${ }^{* *} \mathrm{p}<0.05$; ${ }^{*} \mathrm{p}<0.01$.

Table 4

Total effects results.

\begin{tabular}{|c|c|c|c|c|c|c|}
\hline & \multicolumn{3}{|c|}{ Model 1} & \multicolumn{3}{|c|}{ Model 2} \\
\hline & $\widehat{\beta}$ & t-statistics & $\mathrm{p}$-values & $\widehat{\beta}$ & t-statistics & $\mathrm{p}$-values \\
\hline SysQ $\rightarrow$ EMIS Use & 0.276 & 3.747 & 0.000 & 0.276 & 3.727 & 0.000 \\
\hline IQ $\rightarrow$ EMIS Use & 0.031 & 0.440 & 0.660 & 0.030 & 0.441 & 0.659 \\
\hline SerQ $\rightarrow$ EMIS Use & 0.372 & 6.014 & 0.000 & 0.372 & 6.110 & 0.000 \\
\hline SysQ $\rightarrow$ SS & 0.282 & 4.468 & 0.000 & 0.283 & 4.487 & 0.000 \\
\hline $\mathrm{IQ} \rightarrow \mathrm{SS}$ & 0.366 & 6.295 & 0.000 & 0.365 & 6.332 & 0.000 \\
\hline SerQ $\rightarrow$ SS & 0.204 & 4.015 & 0.000 & 0.205 & 3.925 & 0.000 \\
\hline EMIS Use $\rightarrow$ SS & 0.170 & 3.199 & 0.001 & & & \\
\hline SS $\rightarrow$ EMIS Use & & & & 0.229 & 3.391 & 0.001 \\
\hline SysQ $\rightarrow$ Net Benefits & 0.092 & 1.520 & 0.128 & 0.092 & 1.543 & 0.123 \\
\hline IQ $\rightarrow$ Net Benefits & 0.398 & 7.201 & 0.000 & 0.398 & 7.224 & 0.000 \\
\hline SerQ $\rightarrow$ Net Benefits & 0.352 & 6.999 & 0.000 & 0.352 & 7.026 & 0.000 \\
\hline EMIS Use $\rightarrow$ Net Benefits & 0.227 & 3.908 & 0.000 & 0.476 & 8.632 & 0.000 \\
\hline SS $\rightarrow$ Net Benefits & 0.440 & 7.874 & 0.000 & 0.152 & 3.033 & 0.002 \\
\hline
\end{tabular}

Notes: System quality (SysQ); Information Quality (IQ), Service Quality (SQ), Students Satisfaction (SS).

The "bold" style was used to highlight the results that the Information Quality and Service Quality variables directly have on the Net Benefits (the dependent variable).

\section{Conclusions}

To perform a focused and detailed discussion on the achieved results, we should have a preconceived vision on the status of each posed hypothesis. Table 5 presents a summary on the status of all the research hypothesis defined early in the document.

\subsection{Theoretical and practical implications}

This study aimed at presenting and validating a model of EMIS success, drawing on both Delone and McLean (2003) and Balaban et al. (2013), that incorporated the hypotheses of EMIS quality-related constructs to be direct predictors of net benefits.

From a research perspective, this study represents a contribution to IS theory by finding that information quality (IQ) and service quality (SQ) can act as possible triggers to the arising of net benefits associated with using education management information systems. In fact, and despite this not being included in DeLone and McLean (2016) theoretical arguments on IS success, with the results of our study we can perceive information quality as one of the most important constructs to explain the existence of net 
Table 5

Research hypothesis status after the empirical results have been analysed.

\begin{tabular}{lll}
\hline Code & Hypothesis & Status \\
\hline H1a & A high-quality system will positively influence users towards using it. & Confirmed \\
H1b & A high-quality system will positively trigger students' satisfaction towards its use. & Not Confirmed \\
H1c & A high-quality system will positively trigger the arising of net benefits for students. & Not Confirmed \\
H2a & EMIS capacity to produce high quality information will positively influence its use by students. & Confirmed \\
H2b & EMIS capacity to produce high quality information will positively influence student satisfaction in using it. & Confirmed \\
H2c & EMIS capacity to produce high quality information will influence the arising of net benefits resulting from using the system. & Confirmed \\
H3a & EMIS inherent service quality will act as a positive trigger to its use. & Confirmed \\
H3b & EMIS inherent service quality will act as a positive influence on student satisfaction. & Confirmed \\
H3c & EMIS inherent service quality will act as a positive influence on the arising of net benefits. & Confirmed \\
H4 & EMIS usage by students has a positive effect on their satisfaction in using the system. & Confirmed \\
H5 & EMIS net benefits have a positive impact on EMIS use. & Confirmed \\
H6 & EMIS usage by students has a positive effect on the arising of net benefits for the student. & Confirmed \\
H7 & EMIS net benefits have a positive impact on student satisfaction. & Confirmed \\
\hline
\end{tabular}

benefits from EMIS use. In line with the argument presented by Scott et al. (2011), we have detected that EMIS system quality (i.e. its overall structure, integration ability, reliability and usability) is not a relevant predictor of net benefits.

EMIS usage variation is explained by both model 1 (when EMIS usage explains student satisfaction) and model 2 (when student satisfaction explains EMIS usage) in $40.0 \%$ and $43.2 \%$ respectively. The hypotheses derived from the EMIS quality context (IQ, SysQ and ServQ) to explain the referred system usage are all supported by the results. This is aligned with the existing literature (Al-Debei et al., 2013).

The proposed model also ensures that the relation between EMIS quality and student satisfaction is valid. The model explains $57.6 \%$ in model 1 and $56.0 \%$ in model 2 of the variation in students' satisfaction with EMIS. As argued by Lin (2007) and Tam and Oliveira (2017), EMIS information and service quality is a trigger of user satisfaction and, as a consequence, a positive influence on EMIS use. In a global assumption, the findings presented allow us to perceive that universities should see that their EMIS have wellvalued, organized and updated information and that, at the same time, they ensure the existence of a support service of great efficiency and efficacy. According to Liaw (2008), the proposed model also presents a strong predictive power given the fact that it explains $68.1 \%$ of the net benefits variation.

Despite the presented results suggesting that the overall quality of EMIS has a considerable influence on both system use and student satisfaction, this is not true when student satisfaction explains EMIS usage (model 2), given that in this situation information quality does not represent a predictor of the usage, thus emphasizing that when students are satisfied with their university EMIS, the system information quality does not directly interfere with the usage of the system itself. This indicator should be of some relevance to universities and serve as a trigger for a continued stimulation of students' satisfaction towards the EMIS they must use.

Current results indicate that when a student presents a significant degree of satisfaction with the EMIS he or she must use, there is a growing tendency to continuously use that same system as a tool for managing not only his or her learning process, but also his or her administrative interaction with the institution. This same assumption from the opposite perspective, i.e. EMIS usage impacts student satisfaction, despite being proven it would not enjoy the same strength as the first one (Al-Debei et al., 2013; Tam and Oliveira, 2017).

From a managerial perspective, the posed model and inherent results allow us to raise awareness not only on the mindset towards EMIS quality and its direct impact on system use, student satisfaction, and the arising of net benefits, but also on the possibility of students perceiving to continuously use the system in a different (more positive) manner if they are satisfied with their interaction with the system and the overall results of that same interaction. Thus, university managers, coordinators and technical experts should ensure their EMIS offer high quality information in a structured and coordinated manner and that, at the same time, they provide for a support service that is fully capable of assisting students in using the system when they encounter difficulties.

\subsection{Limitations and future work}

Even though the present research provides some valuable insights into the understanding of education management information system success from a student's perspective, there are some limitations that, from our perspective, should be acknowledged.

Although the respondent sample used includes students from three different universities, thus ensuring a considerable individual profile variety, the achieved results would be able to be generalized if an even wider variety of students had been accessed, from not only other Portuguese universities but also from higher education institutions in other countries. The extension of the data collection task to other national and international institutions should be considered for future work. Another limitation regarding the used sample was the fact that we did not profiled it, thus leading to a concentration of responses in a few academic areas with little to no control of the possible impact that background experience with ICT might have on the students' perception of possible net benefits from EMIS use. This issue represents, from our perspective, a possible trigger for the proposed research model developed, as we believe that students' experience with ICT can possibly act as a moderator of the relation between EMIS quality and EMIS use, students' satisfaction and net benefits. 


\subsection{Final considerations}

Aiming at studying the success of education management information systems from the students' perspective, an initial literature analysis was conducted with the mindset to, first of all, accurately characterize the EMIS concept and all of its characteristics and scope, and secondly, to identify the possible paths towards moving forward and developing a model that was able to characterize the EMIS post-adoption stage, where students might be triggered to pursue a continued use of the referred systems. By drawing its basis on the merge of Delone and McLean (2003) and Balaban et al. (2013) research, we propose a model that assesses the impact of EMIS quality not only on the systems' use and the students' satisfaction, but also on the origin of net benefits.

From the results of the empirical study performed we were able to acknowledge that the origin of net benefits (for students) associated with the existence of EMIS is prompted by the use of the systems and student satisfaction (as referenced literature clearly states), the existence of high-quality and structured information readily available on the EMIS, and the availability of a high-quality EMIS support service.

\section{Acknowledgments}

Mijail Naranjo-Zolotov was funded by the European Commission within the Marie Skłodowska-Curie Actions, International Training Networks (ITN), and European Joint Doctorates (EJD). Grant Agreement number 642332-GEO-C-H2020-MSCA-ITN-2014.

\section{Appendix}

1. Instrument used to measure and assess the students' perception of what might influence EMIS success

\begin{tabular}{|c|c|c|c|}
\hline References & Variable & Cod. & Item \\
\hline \multirow{5}{*}{$\begin{array}{l}\text { Balaban et al. (2013); Delone and } \\
\text { McLean (2003), Gable et al. (2008) }\end{array}$} & System & SYSQ1 & Using my university EMIS is easy to learn. \\
\hline & Quality & SYSQ2 & $\begin{array}{l}\text { Help functions are available and sufficient for using my university } \\
\text { EMIS. }\end{array}$ \\
\hline & & SYSQ3 & $\begin{array}{l}\text { My university EMIS sitemap clearly shows the organization of the } \\
\text { available content. }\end{array}$ \\
\hline & & SYSQ4 & $\begin{array}{l}\text { The existing views (i.e. selected collections of artefacts for self- } \\
\text { presentation) are easy to manage. }\end{array}$ \\
\hline & & SYSQ5 & $\begin{array}{l}\text { My university EMIS includes the necessary features and functions } \\
\text { for me to be able to manage my learning process. }\end{array}$ \\
\hline \multirow[t]{5}{*}{$\begin{array}{l}\text { Au and Ngai (2008), Balaban et al. } \\
\text { (2013), Delone and McLean (2003) }\end{array}$} & $\begin{array}{l}\text { Information } \\
\text { Quality }\end{array}$ & INQ1 & $\begin{array}{l}\text { The information provided about the curricular units taught is } \\
\text { complete. }\end{array}$ \\
\hline & & INQ2 & $\begin{array}{l}\text { The information provided about the curricular units taught is } \\
\text { always up-to-date. }\end{array}$ \\
\hline & & INQ3 & $\begin{array}{l}\text { The information provided about the curricular units taught is } \\
\text { relevant. }\end{array}$ \\
\hline & & INQ4 & $\begin{array}{l}\text { The information provided about the curricular units taught is easy } \\
\text { to understand. }\end{array}$ \\
\hline & & INQ5 & $\begin{array}{l}\text { The information provided about the curricular units taught is in a } \\
\text { readily usable form. }\end{array}$ \\
\hline \multirow{5}{*}{$\begin{array}{l}\text { Balaban et al. (2013), Delone and } \\
\text { McLean (2003), Wang and Wang } \\
\text { (2009) }\end{array}$} & $\begin{array}{l}\text { Service } \\
\text { Quality }\end{array}$ & SEQ2 & $\begin{array}{l}\text { E-mail and other forms of on-line help are available in case of } \\
\text { problems with using the system. }\end{array}$ \\
\hline & & SEQ3 & Teachers/EMIS support staff are helpful for using the system. \\
\hline & & SEQ4 & Teachers/EMIS support staff are competent to answer questions. \\
\hline & & SEQ5 & The institution gives the user individual attention. \\
\hline & & SEQ6 & Teachers/EMIS support staff are always willing to help. \\
\hline \multirow[t]{3}{*}{$\begin{array}{l}\text { Balaban et al. (2013), Delone and } \\
\text { McLean (2003) }\end{array}$} & Use & USE1 & $\begin{array}{l}\text { While using my university EMIS, I use available features for } \\
\text { organizing my content. }\end{array}$ \\
\hline & & USE2 & $\begin{array}{l}\text { While using my university EMIS, I collaborate with my peers or } \\
\text { teachers. }\end{array}$ \\
\hline & & USE3 & $\begin{array}{l}\text { While using my university EMIS, I use features that help me to join } \\
\text { the specific study groups or curricular units. }\end{array}$ \\
\hline
\end{tabular}


Balaban et al. (2013), Delone and McLean (2003), Venkatesh et al. (2003)

Balaban et al. (2013)
User

Satisfaction USAT2 My university EMIS makes work more interesting.

USAT3 Using my university EMIS is a good idea.

USAT4 I find my university EMIS useful in learning.

USAT5 My university EMIS capabilities (e.g. quick upload, format and presentation of personal information, access to content, etc.) are satisfactory.

Net Benefits NETB1 My university EMIS encourages me to develop a positive attitude to Lifelong Learning.

NETB2 My university EMIS helps me to make connections between formal (i.e. structured learning within the school or faculty) and informal (i.e. unstructured learning occurring in everyday life) learning experiences.

NETB3 My university EMIS helps me to fulfil learning outcomes.

NETB4 Using my university EMIS leads to increased transparency in evaluation.

NETB5 I can show my personal growth and development over time.

\section{Appendix A. Supplementary data}

Supplementary data to this article can be found online at https://doi.org/10.1016/j.tele.2018.10.001.

\section{References}

Abdul-Hamid, H., 2017. Building an Education Management Information System in a Fragile Environment: The Case of Afghanistan. Data for Learning: Building a Smart Education Data System. World Bank eLibrary, World Bank, pp. 255-271.

Ahn, T., Ryu, S., Han, I., 2007. The impact of Web quality and playfulness on user acceptance of online retailing. Inf. Manage. 44, $263-275$.

Akaranga, S., Makau, B., 2016. The hermeneutics of education management information systems for Kitinga Primary School in Mwingi Central-Kenya. J. Educ. Pract. 7, 36-40.

Al-Debei, M., Jalal, D., Al-Lozi, E., 2013. Measuring web portals success: a respecification and validation of the DeLone and McLean information systems success model. Int. J. Bus. Inf. Syst. 14, 96-133.

Aldholay, A., Isaac, O., Abdullah, Z., Ramayah, T., 2018. The role of transformational leadership as a mediating variable in DeLone and McLean information system success model: the context of online learning usage in Yemen. Telematics Inf.

Al-Samarraie, H., Teng, B., Alzahrani, A., Alalwan, N., 2017. E-learning continuance satisfaction in higher education: a unified perspective from instructors and students. Studi. Higher Educ. 1-17.

Arkorful, V., Abaidoo, N., 2015. The role of e-learning, advantages and disadvantages of its adoption in higher education. Int. J. Instruct. Technol. Distance Learn. 12, $29-42$.

Au, N., Ngai, E., Cheng, T., 2008. Extending the understanding of end user information systems satisfaction formation: an equitable needs fulfillment model approach. MIS Q. 43-66.

Au-Yong-Oliveira, M., Gonçalves, R., Martins, J., Branco, F., 2018. The social impact of technology on millennials and consequences for higher education and leadership. Telematics Inf. 35, 954-963.

Balaban, I., Mu, E., Divjak, B., 2013. Development of an electronic Portfolio system success model: an information systems approach. Comput. Educ. 60, 396-411.

Baraka, H., Baraka, H., El-Gamily, I., 2013. Assessing call centers' success: a validation of the DeLone and Mclean model for information system. Egypt. Inf. J. 14, 99-108.

Bessa, J., Branco, F., Costa, A., Martins, J., Gonçalves, R., 2016a. A multidimensional information system architecture proposal for management support in Portuguese Higher Education: The university of Tras-os-Montes and Alto Douro case study. In: 2016 11th Iberian Conference on Information Systems and Technologies (CISTI). IEEE, Las Palmas, Spain, pp. 1-7.

Bøe, T., Gulbrandsen, B., Sørebø, Ø., 2015. How to stimulate the continued use of ICT in higher education: integrating information systems continuance theory and agency theory. Comput. Hum. Behav. 50, 375-384.

Branco, F., Martins, J., Gonçalves, R., 2016. Das Tecnologias e Sistemas de Informação à Proposta Tecnológica de um Sistema de Informação Para a Agroindústria: O Grupo Sousacamp RISTI - Revista Ibérica de Sistemas e Tecnologias de Informação, pp. 18-32.

Cash, J., 2015. School Leaders and the Implementation of Education Management Information Systems (EMIS) in the Bahamas: A Case Study of Six Principals. Department of Education, University of Sussex - School of Education and Social Work, pp. 274.

Cenfetelli, R., Benbasat, I., Al-Natour, S., 2008. Addressing the what and how of online services: positioning supporting-services functionality and service quality for business-to-consumer success. Inf. Syst. Res. 19, 161-181.

Chavez, R., Yu, W., Gimenez, C., Fynes, B., Wiengarten, F., 2015. Customer integration and operational performance: the mediating role of information quality. Decis. Support Syst. 80, 83-95.

Cidral, W., Oliveira, T., Di Felice, M., Aparicio, M., 2017. E-learning success determinants: Brazilian empirical study. Comput. Educ. 122, 273-290.

Collins, A., Halverson, R., 2018. Rethinking Education in the Age of Technology: The digital Revolution and Schooling in America. Teachers College Press.

Cruz-Jesus, F., Vicente, M., Bacao, F., Oliveira, T., 2016. The education-related digital divide: an analysis for the EU-28. Comput. Hum. Behav. 56, 72-82.

Davis, B., Sumara, D., 2014. Complexity and Education: Inquiries into Learning, Teaching, and Research. Routledge.

Delone, W., McLean, E., 2003. The DeLone and McLean model of information systems success: a ten-year update. J. Manage. Inf. Syst. 19, 9-30.

Delone, W., Mclean, E., 2004. Measuring e-commerce success: applying the DeLone \& McLean information systems success model. Int. J. Electron. Commerce 9, 31-47. DeLone, W., McLean, E., 2016. Information systems success measurement Foundations and Trends ${ }^{\circledR}$. Inf. Syst. 2, 1-116.

Deng, L., Tavares, N., 2013. From Moodle to Facebook: exploring students' motivation and experiences in online communities. Comput. Educ. 68, 167-176.

Faria, A., Almeida, A., Martins, C., Gonçalves, R., Martins, J., Branco, F., 2017. A global perspective on an emotional learning model proposal. Telematics Inf. 34, 824-837.

Floropoulos, J., Spathis, C., Halvatzis, D., Tsipouridou, M., 2010. Measuring the success of the Greek taxation information system. Int. J. Inf. Manage. 30, 47-56. Fornell, C., Larcker, D., 1981. Structural equation models with unobservable variables and measurement error: algebra and statistics. J. Market. Res. 382-388. 
Gable, G., Sedera, D., Chan, T., 2008. Re-conceptualizing information system success: the IS-impact measurement model. J. Assoc. Inf. Syst. 9, 377.

Gorla, N., Somers, T., Wong, B., 2010. Organizational impact of system quality, information quality, and service quality. J. Strategic Inf. Syst. 19, $207-228$.

Greenhow, C., Robelia, B., Hughes, J.E., 2009. Learning, teaching, and scholarship in a digital age: Web 2.0 and classroom research: what path should we take now? Educ. Res. 38, 246-259.

Hair Jr., J.F., Hult, G.T.M., Ringle, C., Sarstedt, M., 2016. A Primer on Partial Least Squares Structural Equation Modeling (PLS-SEM). Sage Publications.

Hair, J., Ringle, C., Sarstedt, M., 2013. Partial least squares structural equation modeling: rigorous applications. better results and higher acceptance. Long Range Plan. $46,1-12$.

Henseler, J., Ringle, C., Sinkovics, R., 2009. The use of partial least squares path modeling in international marketing. In: New Challenges to International Marketing. Emerald Group Publishing Limited, pp. 277-319.

Henseler, J., Ringle, C., Sarstedt, M., 2015. A new criterion for assessing discriminant validity in variance-based structural equation modeling. J. Acad. Mark. Sci. 43, $115-135$.

Holsapple, C., Lee-Post, A., 2006. Defining, assessing, and promoting e-learning success: an information systems perspective. Decis. Sci. J. Innov. Educ. 4, 67-85.

Hong, S., Thong, J., Tam, K., 2006. Understanding continued information technology usage behavior: a comparison of three models in the context of mobile internet. Decis. Support Syst. 42, 1819-1834.

Hsiao, C., Chang, J., Tang, K., 2016. Exploring the influential factors in continuance usage of mobile social Apps: satisfaction, habit, and customer value perspectives. Telematics Inf. 33, 342-355.

Hua, H, Herstein, J., 2003. Education management information system (EMIS): Integrated data and information systems and their implications in educational management. Annual Conference of Comparative and International Education Society, pp. 26.

Kim, S., Malhotra, N., 2005. A longitudinal model of continued IS use: an integrative view of four mechanisms underlying postadoption phenomena. Manage. Sci. 51, $741-755$.

Koç, T., Turan, A., Okursoy, A., 2016. Acceptance and usage of a mobile information system in higher education: an empirical study with structural equation modeling The International. J. Manage. Educ. 14, 286-300.

Laumer, S., Maier, C., Weitzel, T., 2017. Information quality, user satisfaction, and the manifestation of workarounds: a qualitative and quantitative study of enterprise content management system users. Eur. J. Inf. Syst. 26, 333-360.

Lee, J., Lee, W., 2008. The relationship of e-Learner's self-regulatory efficacy and perception of e-Learning environmental quality. Comput. Hum. Behav. 24, 32-47.

Liaw, S., 2008. Investigating students' perceived satisfaction, behavioral intention, and effectiveness of e-learning: a case study of the Blackboard system. Comput. Educ. 51, 864-873.

Lin, H., 2007. Measuring online learning systems success: applying the updated DeLone and McLean model. Cyberpsychol. Behav. 10, 817-820.

Martins, J., Branco, F., Au-Yong-Oliveira, M., Gonçalves, R., Moreira, F., 2019.. Higher education students perspective on education management information systems: an initial success model proposal. Int. J. Technol. Hum. Interact. (IJTHI) 15.

Martins, J., Gonçalves, R., Santos, V., Cota, M., Oliveira, T., Branco, F., 2015. Proposta de um Modelo de e-Learning Social RISTI - Revista Ibérica de Sistemas e Tecnologias de Informação vol. 16, pp. 92-107.

Masino, S., Niño-Zarazúa, M., 2016. What works to improve the quality of student learning in developing countries? Int. J. Educ. Dev. 48, 53-65.

Mavetera, P., Lubbe, S., Jan, A., 2017. A student perspective into information quality of web sites. Afr. J. Inf. Syst. 9 , 1.

McGill, T., Klobas, J., 2009. A task-technology fit view of learning management system impact. Comput. Educ. 52, $496-508$.

Michel, S., Cocula, F., 2017. Impact of the three IS qualities on user satisfaction in an information-intensive sector. Electron. J. Inf. Syst. Eval. 20, 85-101.

Moreira, F., Rocha, Á., 2018. A Special Issue on Disruption of higher education in the 21st century due to ICTs. Telematics Inf. 35, $930-932$.

Navimipour, N., Zareie, B., 2015. A model for assessing the impact of e-learning systems on employees' satisfaction. Comput. Hum. Behav. 53 , 475-485.

Oliveira, T., Faria, M., Thomas, M., Popovič, A., 2014. Extending the understanding of mobile banking adoption: when UTAUT meets TTF and ITM. Int. J. Inf. Manage. 34, 689-703.

Park, E., Kim, K., 2014. An integrated adoption model of mobile cloud services: exploration of key determinants and extension of technology acceptance model. Telematics Inf. 31, 376-385.

Ringle, C.M., Wende, S., Becker, J.-M., 2015. SmartPLS. SmartPLS GmbH, 3 Boenningstedt.

Sanchez-Gordon, S., luján-Mora, S., 2016. How could MOOCs become accessible? The case of EdX and the future of inclusive online learning. J. Universal Comput. Sci. 2, 55-81.

Scott, M., DeLone, W., Golden, W., 2011. IT quality and egovernment net benefits: a citizen perspective. ECIS 87.

Straub, D., 1989. Validating instruments in MIS research. MIS Q. 147-169.

Sun, H., 2013. A longitudinal study of herd behavior in the adoption and continued use of technology. Mis Q. 37.

Tam, C., Oliveira, T., 2017. Understanding mobile banking individual performance: the DeLone \& McLean model and the moderating effects of individual culture. Internet Res. 27, 538-562.

Tarafdar, M., Gordon, S.R., 2007. Understanding the influence of information systems competencies on process innovation: a resource-based view. J. Strategic. Inf. Syst. 16, 353-392.

Tolley, H., Shulruf, B., 2009. From data to knowledge: the interaction between data management systems in educational institutions and the delivery of quality education. Comput. Educ. 53, 1199-1206.

University of Stuttgart. Online applications for University of Stuttgart. 2016.

Välimaa, J., Hoffman, D., 2008. Knowledge society discourse and higher education. High. Educ. 56, $265-285$.

Venkatesh, V., Morris, M., Davis, G., Davis, F., 2003. User acceptance of information technology: toward a unified view. MIS Q. $425-478$.

Vicent, L., Villagrasa, S., Fonseca, D., Redondo, E., 2015. Virtual learning scenarios for qualitative assessment in higher education 3D arts. J. Universal Comput. Sci. 21, 1086-1105.

Waheed, M., Kaur, K., Kumar, S., 2016. What role does knowledge quality play in online students' satisfaction, learning and loyalty? An empirical investigation in an eLearning context. J. Comput. Assisted Learn. 32, 561-575.

Walji, M., Kalenderian, E., Piotrowski, M., Tran, D., Kookal, K., Tokede, O., White, J., Vaderhobli, R., Ramoni, R., Stark, P., 2014. Are three methods better than one? A comparative assessment of usability evaluation methods in an EHR. Int. J. Med. Inf. 83, 361-367.

Wang, Y., Liao, Y., 2008. Assessing eGovernment systems success: a validation of the DeLone and McLean model of information systems success. Gov. Inf. Q. 25, $717-733$.

Wang, Y., Shih, Y., 2009. Why do people use information kiosks? A validation of the Unified Theory of Acceptance and Use of Technology. Gov. Inf. Q. 26, 158-165.

Wang, W., Wang, C., 2009. An empirical study of instructor adoption of web-based learning systems. Comput. Educ. 53, 761-774.

Wong, W., Huang, N., 2015. The effects of e-learning system service quality and users' acceptance on organizational learning. Int. J. Bus. Inf. 6.

Wu, J., Wang, Y., 2006. Measuring KMS success: a respecification of the DeLone and McLean's model. Inf. Manage. 43, 728-739.

Yang, M., Shao, Z., Liu, Q., Liu, C., 2017. Understanding the quality factors that influence the continuance intention of students toward participation in MOOCs. Educ. Technol. Res. Dev. 65, 1195-1214.

Yoo, S., Huang, W., 2013. Engaging online adult learners in higher education: motivational factors impacted by gender, age, and prior experiences. J. Continuing Higher Educ. 61, 151-164.

Yousapronpaiboon, K., 2014. SERVQUAL: measuring higher education service quality in Thailand. Procedia-Soc. Behav. Sci. 116, $1088-1095$.

Zheng, Y., Zhao, K., Stylianou, A., 2013. The impacts of information quality and system quality on users' continuance intention in information-exchange virtual communities: an empirical investigation. Decis. Support Syst. 56, 513-524.

Zhou, T., 2013. An empirical examination of continuance intention of mobile payment services. Decis. Support Syst. 54, $1085-1091$.

Zolotov, M., Oliveira, T., Casteleyn, S., 2017. E-participation adoption models research in the last 17 years: a weight and meta-analytical review. Comput. Hum. Behav. $81,350-365$. 